Article

\title{
Kinetic and Isotherm Studies Biochar on Ammonium Solution
}

\author{
Sohaimi KSA ${ }^{1}$ * Ong $\mathrm{CS}^{2}$, Iberahim $\mathrm{NI}^{3}$ and Mohamed AR ${ }^{4}$, Zainol $\mathrm{NA}^{5}$ \\ 1 Faculty of Chemical Engineering Technology, Universiti Malaysia Perlis, Sungai Chuchuh, 02100, Padang \\ Besar, Perlis, Malaysia; syairah@unimap.edu.my \\ 2 Faculty of Chemical Engineering Technology, Universiti Malaysia Perlis, Sungai Chuchuh, 02100, Padang \\ Besar, Perlis, Malaysia; chyhshyang1001@outlook.com \\ 3 Faculty of Chemical Engineering Technology, Universiti Malaysia Perlis, Sungai Chuchuh, 02100, Padang \\ Besar, Perlis, Malaysia; izzatiiberahim@unimap.edu.my \\ 4 Faculty of Chemical Engineering Technology, Universiti Malaysia Perlis, Sungai Chuchuh, 02100, Padang \\ Besar, Perlis, Malaysia; alina@unimap.edu.my \\ 5 Faculty of Chemical Engineering Technology, Universiti Malaysia Perlis, Sungai Chuchuh, 02100, Padang \\ Besar, Perlis, Malaysia; aineezainol@unimap.edu.my
}

* Correspondence syairah@unimap.edu.my; Tel.: (+06-13-73388133)

\begin{abstract}
Sewage sludge was utilized into biochar using the slow pyrolysis method. The biochar was then being used for ammonium removal. The sewage sludge biochar was produced at temperature of $550^{\circ} \mathrm{C}, 600^{\circ} \mathrm{C}, 650^{\circ} \mathrm{C}, 700^{\circ} \mathrm{C}$ and $750^{\circ} \mathrm{C}$. A few characterization tests were carried out to study about the physical and chemical properties of the biochar. For instance, moisture and ash content analysis, FTIR spectroscopy, pH Zero Point Charge, biochar yield and SEM. As the pyrolysis temperature increased, the moisture content of SSB decreased while the ash content increased. The FTIR spectra of sewage sludge biochar showed that there were various organic functional groups on the surface of the biochar which were responsible for ammonium adsorption. Furthermore, through pH Zero Point Charge analysis, $\mathrm{pH} 7.0$ was the most optimum $\mathrm{pH}$ for the adsorption test of ammonium. The optimum adsorbent dosage was $0.01 \mathrm{~g}$ while optimum contact time was 150 minutes. Furthermore, $1.2 \mathrm{ppm}$ was the most optimum concentration for adsorption process. Based on the result of the characterization tests, SSB700 was the most effective biochar for ammonium adsorption. Based on the result of kinetic and isotherm analysis, the adsorption of ammonium ions usign sewage sludge biochar was a monolayer chemisorption process.
\end{abstract}

Keywords: Sewage sludge, biochar, adsorption, ammonium, kinetic, isotherm

\section{Introduction}

In modern days, with the rapid evolution of the industry, improper disposal of industrial wastewater containing huge quantities of ammonium has caused eutrophication issues in lakes, rivers and other water reservoirs [1]. Eutrophication is one of the major environmental problems where the water body becomes enriched in dissolved nutrients such as ammonium. The presence of these dissolved nutrients will cause an accelerated growth of algae or other high forms of plant life. This will lead to an undesirable disturbance to the balance of organisms exist in the water and to the quality of water concerned. Therefore, effective removal of ammonium ions from water source is crucial. Adsorption method has proven to be one of the most favoured method to remove ammonium from water source. This is mainly due to its environmental and economic sustainability [2]. Hence, in this research, study regarding the adsorption of ammonium ions using sewage sludge biochar will be conducted. 


\section{Materials and Methods}

\subsection{Sample preparation}

The sewage sludge from the Kilang Gula Felda Perlis was washed three times with tap water to remove dust and surface impurities. Then, the sewage sludge was dried in the drying oven for 24 hours at $105{ }^{\circ} \mathrm{C}$ to remove water inside the sewage sludge completely [3]. The dried sewage sludge was grinded into smaller size of 1 to $2 \mathrm{~mm}$ in diameter in a commercial grinder and subsequently homogenized by sieving. The desired particle size was $250 \mu \mathrm{m}$. The treated sample was stored inside an air-tight plastic bag and subjected to the process of pyrolysis.

\subsection{Slow pyrolysis process}

The pyrolysis of sewage sludge was carried out in the muffle furnace at five different temperatures $\left(550{ }^{\circ} \mathrm{C}, 600^{\circ} \mathrm{C}, 650^{\circ} \mathrm{C}, 700{ }^{\circ} \mathrm{C}\right.$ and $750{ }^{\circ} \mathrm{C}$ ). Each time $10 \mathrm{~g}$ of dried sewage sludge was weighed using an electronic weighing balance and placed into the pre-weighed porcelain crucible. Next, the porcelain crucible was placed into the muffle furnace for pyrolysis process. The pyrolysis heating rate was employed at $10{ }^{\circ} \mathrm{C} / \mathrm{min}$ and the sewage sludge was carbonized for 1 hour [3]. The biochar produced was being cooled down to room temperature for 10 hours. The biochar was labelled as SSB550, SSB600, SSB650, SSB700 and SSB750 based on the temperature of pyrolysis. Then, the biochar was stored inside a sealed plastic container until use.

\subsection{Biochar characterization}

\subsubsection{Moisture and ash analysis}

The moisture content analysis was carried out based on the American Society for Testing and Materials (ASTM) standard. Approximately $1 \mathrm{~g}$ of biochar was added into the crucible and weighed together using electronic weighing balance to the nearest $0.1 \mathrm{mg}$. The sample was dried in the drying oven at $105^{\circ} \mathrm{C}$ for 2 hours. After that, the dried sample was cooled in the desiccator for 1 hour and weighed. The mass loss of the sample after the drying process was used to calculate the moisture content of the sewage sludge biochar [4].

As for the determination of the ash content of the biochar, lids and the uncovered porcelain crucible containing the sample were placed in the muffle furnace at $750^{\circ} \mathrm{C}$ for 6 hours. The crucibles with lids were cooled in the desiccator for 1 hour and weighed. The burning of the sample was repeated until succeeding 1 -h period of heating results in a loss less than $0.5 \mathrm{mg}$ [4].

\subsubsection{FTIR Analysis}

The functional groups and chemical composition of the biochar samples were determined using the $\mathrm{KBr}$ pellets containing $1 \%$ of each sample by Fourier Transform Infrared Spectroscopy (FTIR) (Perkin Elmer Spectrum 65, Perkin Elmer Inc, USA). The biochar sample of particle sizes $250 \mu \mathrm{m}$ was first dried in the dry oven overnight at $105^{\circ} \mathrm{C}$ before generating the spectra. The resulting spectra was normalized to the peak in the region between 4000 and $400 \mathrm{~cm}-1$ with 100 scans per sample. The previously recorded background spectrum of $\mathrm{KBr}$ was subtracted from the spectrum of each sample [3].

\subsection{3 $\mathrm{pH}$ zero point charge $\left(\mathrm{pH} \mathrm{H}_{z \mathrm{c}}\right.$ )}

$\mathrm{pH}$ zpc values of various biochar samples were measured by $\mathrm{pH}$ drift method. The $\mathrm{pH}$ values of $0.01 \mathrm{~mol} / \mathrm{L} \mathrm{NaCl}$ solutions were adjusted to a range of 2 to 10 using $0.1 \mathrm{~mol} / \mathrm{L} \mathrm{HNO}_{3}$ and $0.1 \mathrm{~mol} / \mathrm{L}$ $\mathrm{NaOH}$. Then, $0.2 \mathrm{~g}$ of biochar sample was weighed and added into $10 \mathrm{ml}$ of $\mathrm{NaCl}$ solutions. The 
mixture was shaken at $180 \mathrm{rpm}$ at $25^{\circ} \mathrm{C}$ for 24 hours. After 24 hours, the final $\mathrm{pH}$ of solutions was measured using the microprocessor $\mathrm{pH}$ meter. A graph of final $\mathrm{pH}$ versus initial $\mathrm{pH}$ was plotted. Intersection point of the resulting curve with the line passing through the origin (final $\mathrm{pH}=$ initial $\mathrm{pH}$ ) gave the value of $\mathrm{pH}$ zpc [5].

\subsubsection{Yield}

The yield of biochar is defined as the ratio of the produced biochar weight to the dry weight of sewage sludge subjected to pyrolysis. The produced biochar was weighed after cooling down [5].

\subsubsection{SEM Analysis}

Scanning electron microscopy (SEM) (Hitachi TM 3000) was used to study the surface morphology of biochar samples produced under different temperature of pyrolysis. The samples were held onto adhesive carbon tape on an aluminium stub followed by sputter coating with gold. SEM images of biochar samples were obtained using a scanning electron microscope (SEM) Quanta $3 \mathrm{D}, \mathrm{FEG}$ and FEI with an accelerating voltage of $2.00 \mathrm{kV}$ in a high vacuum mode [5].

\subsection{Batch adsorption equilibrium experiment}

\subsection{1pH of ammonium solution}

Five $50 \mathrm{~mL}$ samples of ammonium solution with $\mathrm{pH} 2,4,6,8$ and 10 were prepared. The adsorption process was carried out by agitating the desired $\mathrm{pH}$ ammonium solution with $0.1 \mathrm{~g}$ of biochar sample inside at $30^{\circ} \mathrm{C}$ and rotational speed of $250 \mathrm{rpm}$ for 150 minutes [5].

\subsubsection{Adsorbent usage}

Five biochar samples with dosage of $0.1 \mathrm{~g}, 0.2 \mathrm{~g}, 0.3 \mathrm{~g}, 0.4 \mathrm{~g}$ and $0.5 \mathrm{~g}$ will be prepared respectively. $50 \mathrm{~mL}$ of $1.2 \mathrm{ppm}$ ammonium solution was used for each sample. The adsorption process was carried out at $30^{\circ} \mathrm{C}, 250 \mathrm{rpm}, \mathrm{pH} 7$ for 150 minutes [5].

\subsubsection{Contact time of adsorption}

The contact time between the ammonium solution and biochar adsorbent were varied such as 10 minutes, 20, 40, 60, 80, 100, 120, 150, 200 and 240 minutes. $0.1 \mathrm{~g}$ of biochar was placed into the shaking flasks containing $50 \mathrm{~mL}$ of $1.2 \mathrm{ppm}$ of ammonium solution and adsorption process was took place with the agitation of the flasks containing ammonium solution with biochar in it. The adsorption process was carried out at $30^{\circ} \mathrm{C}$ and $250 \mathrm{rpm}$ at $\mathrm{pH} 7$ [5].

\subsubsection{Initial concentration of ammonium solution}

Five different concentration of ammonium solutions were used including $0.4 \mathrm{ppm}, 0.6 \mathrm{ppm}, 0.8$ ppm, $1.0 \mathrm{ppm}$ and $1.2 \mathrm{ppm}$. 0.1g of biochar was added into shaking flasks containing $50 \mathrm{~mL}$ of different concentration of ammonium solution respectively. The adsorption process took place with the agitation of the flasks containing ammonium solution with biochar in it. The process was carried out at $30^{\circ} \mathrm{C}, 250 \mathrm{rpm}$ and $\mathrm{pH} 7$ for 150 minutes [5]. 


\subsection{Adsorption kinetic experiments}

For kinetic study, about $0.1 \mathrm{~g}$ of the biochar was mixed with $50 \mathrm{ml}$ of ammonium solution with concentration of $1.2 \mathrm{ppm}$ in the flasks. The mixture was shaken in the sieve shaker $(250 \mathrm{rpm})$ at $30^{\circ} \mathrm{C}$. At different time interval of 10, 20, 40, 60, 80, 100, 120, 150, 200 and 240 minutes, some of the flasks were withdrawn from the shaker. Pseudo-first order and Pseudo-second order kinetic models were used to analyse the obtained data [5].

\subsection{Adsorption isotherm experiments}

For isotherm study, about $0.1 \mathrm{~g}$ of the biochar was mixed with $50 \mathrm{ml}$ of ammonium solution of different initial concentration. For instance, $0.4,0.6,0.8,1.0$ and $1.2 \mathrm{ppm}$. The mixture was shaken in the incubator sieve shaker at $\mathrm{pH} 7$ and $250 \mathrm{rpm}$ for 150 minutes. Two main isotherm models, Langmuir model (LM) and Freundlich model (FM) were used to describe the experimental result of ammonium adsorption [5].

\section{Results}

\subsection{Moisture and ash content analysis}

The weight loss of drying process in moisture content analysis is attributed to the evaporation of water from the surface of biochar. According to Figure 1, the moisture content of the biochar decreased as the pyrolysis temperature increased from $17 \%$ at $550^{\circ} \mathrm{C}$ to $1 \%$ at $750^{\circ} \mathrm{C}$. Such phenomenon was mainly due to increment of the rate of drying as temperature increased. Hence, more water was being removed from the surface of biochar as the pyrolytic temperature increased. From Figure 1, SSB700 and SSB750 were ideal as their moisture content was the lowest [6].

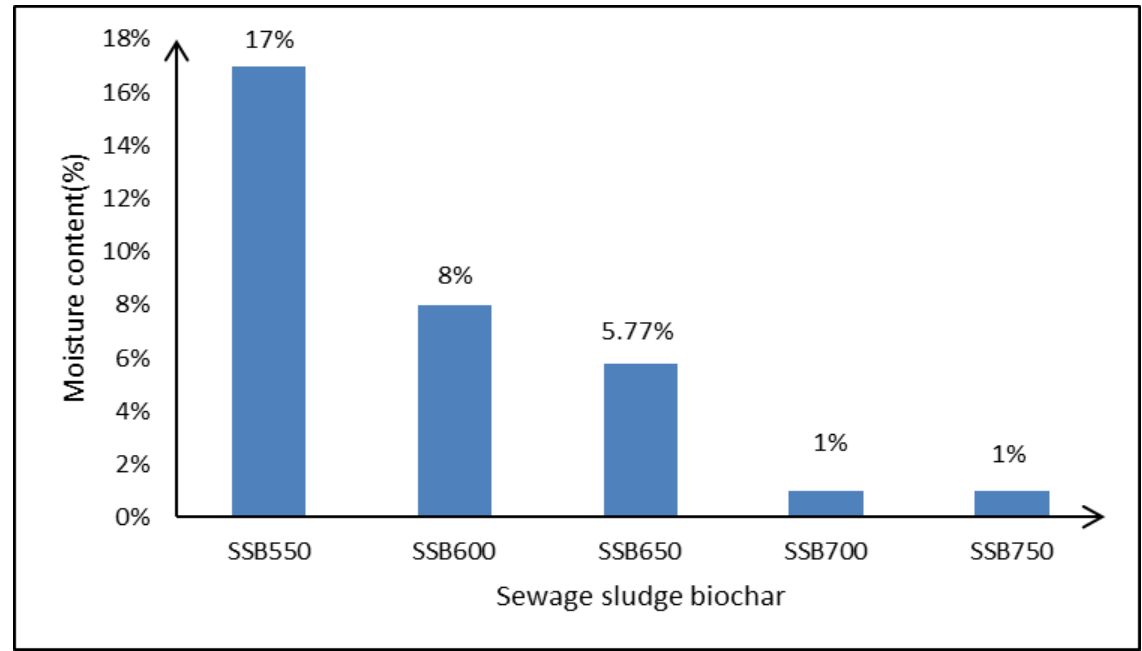

Figure 1. Moisture content analysis of sewage sludge biochar

The weight loss of burning process in ash content analysis is attributed to the production of ash. According to Figure 2, the biochar experienced a slight increment in terms of ash content as the pyrolysis temperature increased from $58.76 \%$ at $550^{\circ} \mathrm{C}$ to $61.16 \%$ at $750^{\circ} \mathrm{C}$.One of the main reasons was due to the catalytic volatilization of organic matter in the presence of inorganic minerals [6]. 


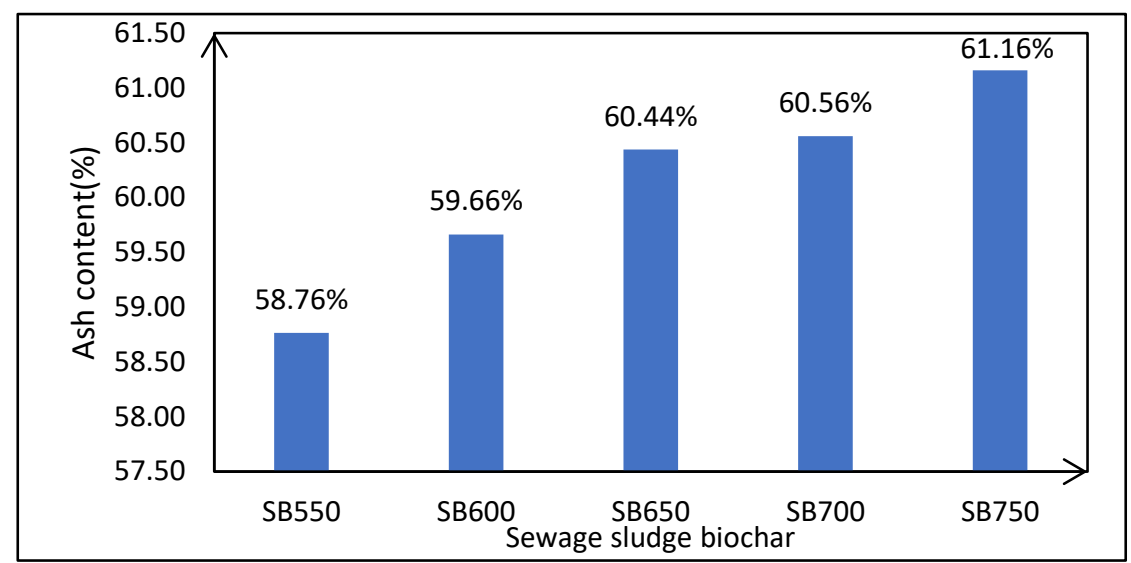

Figure 2. Ash content analysis of sewage sludge biochar

\subsection{FTIR Analysis}

According to Figure 3, many different adsorption peaks were discovered, which represented the various functional groups found on the surface of the biochar as well as the complexity nature of biochar. The adsorption peaks located at the range of $3500-3300 \mathrm{~cm}^{-1}$ were assigned to O-H stretching (alcohol) and broad of intramolecular $\mathrm{H}$ bonds. The intensity of the peak at $3402.20 \mathrm{~cm}^{-1}$ decreased rapidly from raw sludge to biochar samples. This implied that many hydroxyl groups were being decomposed due to dehydration and dehydrogenation reaction during the sewage sludge pyrolysis at elevated temperature $[\mathrm{x}]$. The peak at range of $1800-1600 \mathrm{~cm}^{-1}$ can be referred to the $\mathrm{N}-\mathrm{H}$ bending, amide bond stretching $(\mathrm{C}=\mathrm{O})$ and others. This was due to the presence of primary ammine in the sewage sludge [7]. Furthermore, the adsorption peak $(1418.45 \mathrm{~cm}-1)$ found on the raw sludge indicated the presence of aromatic groups as well. $\mathrm{C}=\mathrm{O}$ and $\mathrm{C}=\mathrm{C}$ bonds. This band was also related to the deformation of $\mathrm{NH}_{4}{ }^{+}$, thereby indicating the removal of $\mathrm{NH}_{4}{ }^{+}$onto SSB700 was mainly via chemisorption [7]. As conclusion, FTIR analysis showed the presence of organic functional groups which played an important role in the adsorption of ammonium.

\section{3 pH zero point charge $\left(p H_{z p c}\right)$}

Point of zero charge was determined with a graph of final $\mathrm{pH}, \mathrm{pHf}$ versus initial $\mathrm{pH}, \mathrm{pHi}$. Pashai Gatabi et al. (2016) reported that $\mathrm{pH}$ zero charge for sewage sludge biochar was obtained at 7 . According to Figure 4, only SSB 700 shows such result where the final $\mathrm{pH}$ was 7.07 when the initial $\mathrm{pH}$ was 7. Therefore, $\mathrm{pH} 7$ was considered as the optimum $\mathrm{pH}$ for adsorption while SSB700 was selected as the biochar being used for the adsorption test later. 


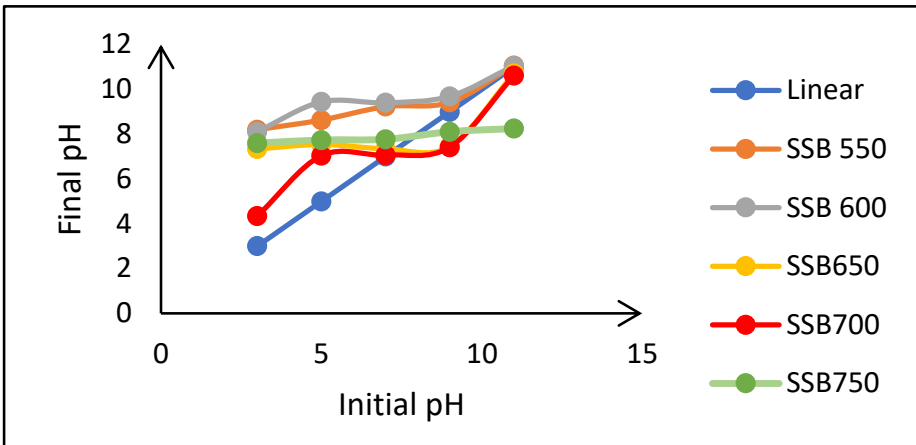

Figure 4. $\mathrm{pH}$ zero point charge for sewage sludge biochar

\subsection{Yield}

According to Figure 5, biochar yield was noticed to be slightly decreased with increasing temperature from $88.32 \%$ at $550^{\circ} \mathrm{C}$ to $84.18 \%$ at $750^{\circ} \mathrm{C}$. The pyrolysis yield obtained for the sewage sludge was distinctly higher than those for plant biomass [8] and pyrolyzed sewage sludge by other authors [8]. A high yield was mainly due to higher inorganic content as well as low moisture content in the sewage sludge. Lower yield as temperature increased was a typical process in the case of sewage sludge [8]. This was because there was greater decomposition of raw materials higher temperature [8].

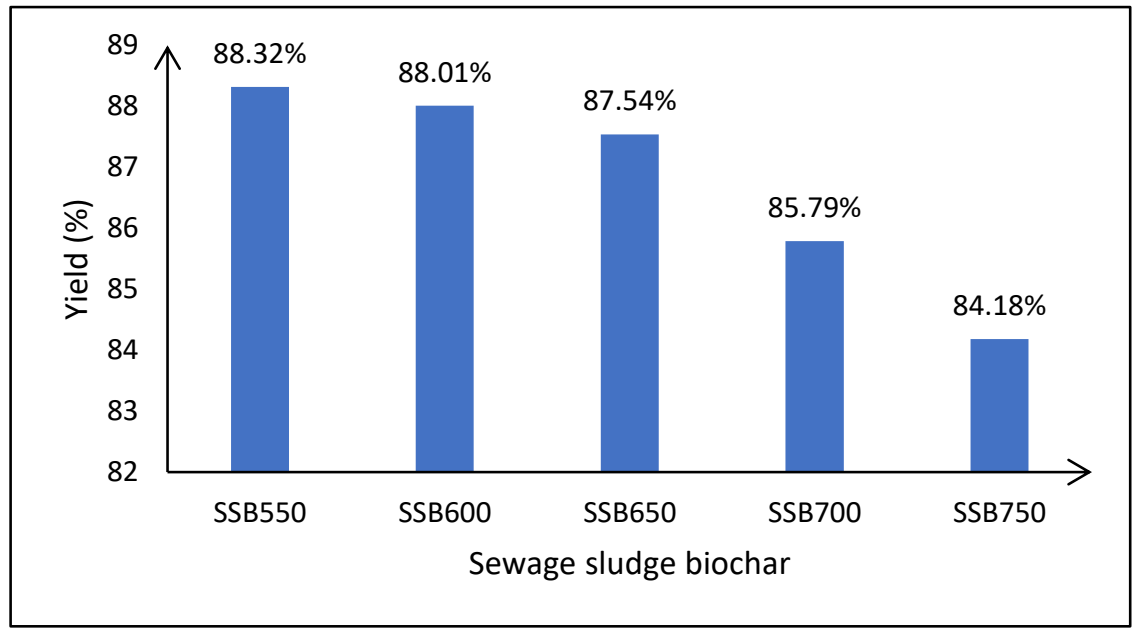

Figure 5. Percentage yield of sewage sludge biochar

\subsection{SEM analysis}

Figure 6 below shows the SEM images of raw sludge, SSB550 and SSB700. As can be seen, the surface morphology of the samples was extremely rich. Besides, through SEM, the porous structures were seen and different forms were observed. For example, fluffy sponges, balls and simply small formless particles. These structures could benefit the water permeation, thus making the $\mathrm{NH}_{4}{ }^{+}$easily accessible [8]. It was also observed that there were few pores on the surface of biochars derived at lower temperature. This was because at lower temperature, some of volatile matter found on the surface of biochar were not volatized yet. 


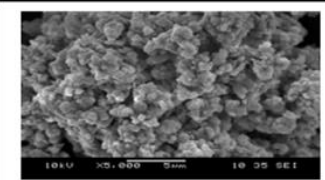

Raw sludge (x 5000)

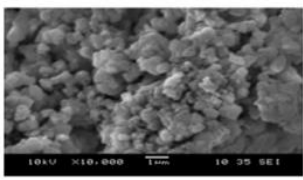

SB550 (x 10000)

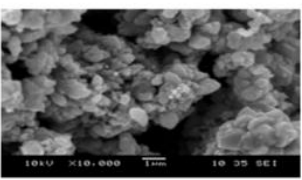

SB700 (x 10000)

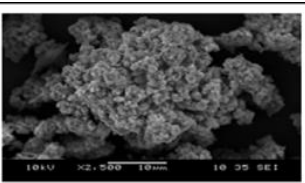

Raw sludge (x 2500)

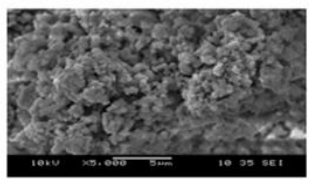

SB550 (x 5000)

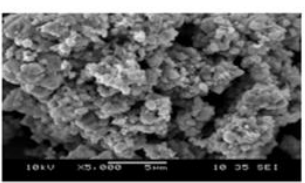

$\mathrm{SB} 700(\mathrm{x} 5000)$

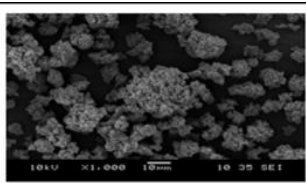

Raw sludge (x 1000)

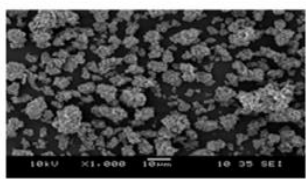

SB550 (x 1000)

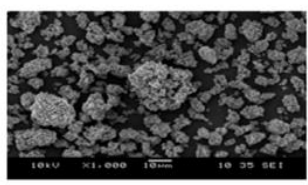

SB700 (x 1000)

Figure 6. SEM images of sewage sludge biochar under different magnification

\subsection{Effects of parameters on adsorption process}

\subsubsection{Effect of adsorbent dosage}

As illustrated in Figure 7, the adsorption capacity of biochar SSB700 decreased with the increase of adsorbent dosage from $0.1 \mathrm{~g}$ to $0.5 \mathrm{~g}$. This effect can be attributed to a decrease number of active surface sites for the ammonium thereby significantly reducing the adsorption capacity [9]. This was mainly due to the overlapping of adsorbent layers.

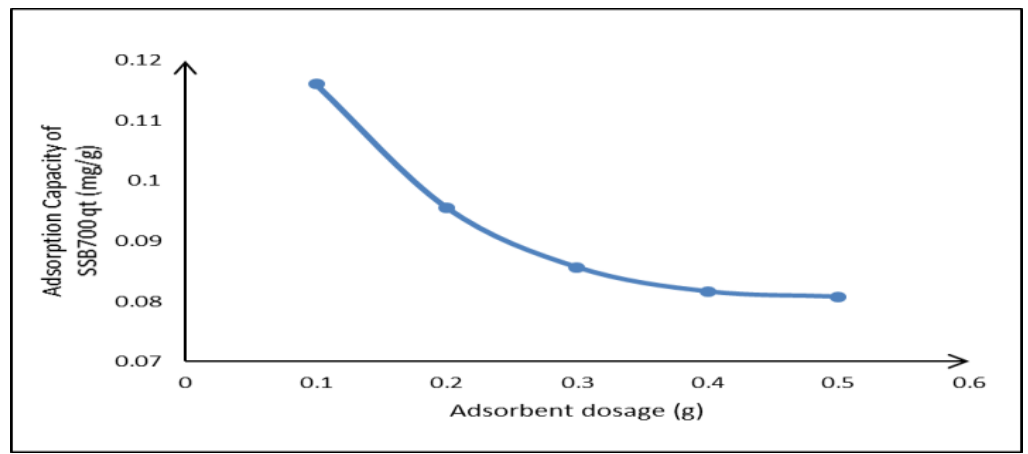

Figure 7. Graph of Adsorption Capacity of Biochar SSB700, qt (mg/g) against Adsorbent Dosage (g)

\subsubsection{Effect of contact time of adsorption}

As illustrated in Figure 8, it can be seen that the adsorption capacity was rapid at the first stage of adsorption (0-20 minutes), then slowly increased with time (20-150 minutes), and becoming almost constant after 150 minutes (150 minutes onwards). This phenomenon was due to the high availability of vacant sites in the first stage of adsorption [9]. The adsorption was then followed by an increase in replusive forces due to the presence of the adsorbed ions. The adsorption process continued to a point where the adsorbent was not able to adsorb the surrounding adsorbates due to the lack of vacant sites. In this study, the optimum contact time was 150 minutes. 


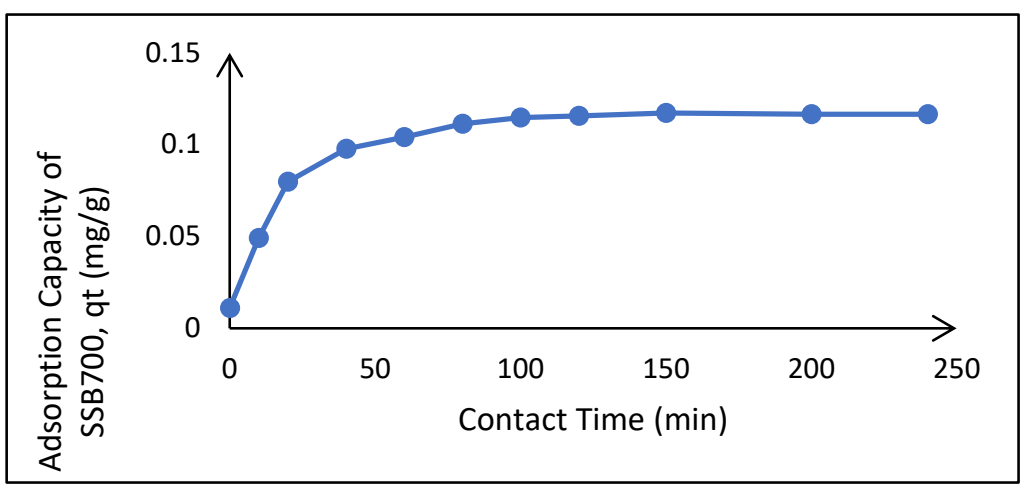

Figure 8. Graph of Adsorption Capacity of Biochar SSB700, $\mathrm{q}_{\mathrm{t}}$ $(\mathrm{mg} / \mathrm{g})$ against Contact Time $(\mathrm{min})$

\subsubsection{Effect of initial concentration of ammonium solution}

From Figure 9, it was obvious that by increasing the initial concentration of ammonium solution from $0.4 \mathrm{ppm}$ to $1.2 \mathrm{ppm}$, the adsorption capacity of the biochar SSB700 increased from $0.0236 \mathrm{mg} / \mathrm{g}$ to $0.1161 \mathrm{mg} / \mathrm{g}$. It was because higher ammonium concentration provided a greater driving force for adsorption as more $\mathrm{NH}_{4}+$ ions can be adsorbed by the SSB700 [9].

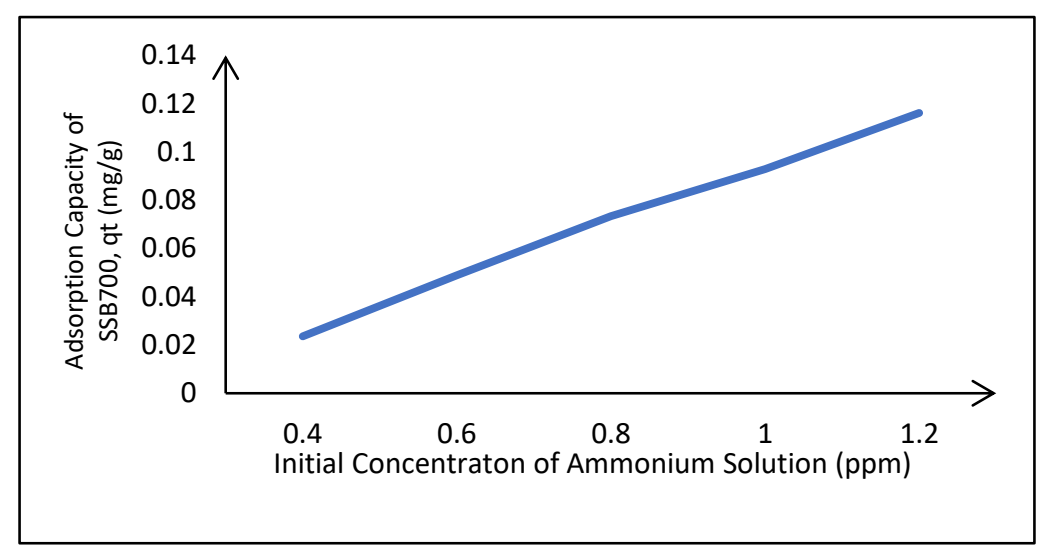

Figure 9. Graph of Adsorption Capacity of Biochar SSB700, $\mathrm{q}_{\mathrm{t}}$ (mg/g) against Initial Concentration of Ammonium Solution (ppm)

\subsection{Kinetic analysis}

The adsorption kinetic was studied by varying the contact time for adsorption (10 minutes, 20 minutes, 40 minutes, 60 minutes, 80 minutes, 100 minutes and 120 minutes). Table 1 illustrates the kinetic parameters of $\mathrm{NH}_{4}{ }^{+}$adsorption by sewage sludge biochar (SSB700) using kinetic models. The pseudo-second-order rate equation for $\mathrm{NH}_{4}{ }^{+}$adsorption onto the sewage sludge biochar had a better fit with high $\mathrm{R}_{2}\left(\mathrm{R}_{2}=0.9978\right)$. Thus, this indicated that the chemisorption dominated in the adsorption [10].

Table 1. The kinetic parameters of $\mathrm{NH}_{4}{ }^{+}$adsorption by sewage sludge biochar (SB700) for Pseudo- 


\begin{tabular}{ccc}
\hline Kinetic model & Pseudo-first-order & Pseudo-second-order \\
\hline $\mathrm{R}^{2}$ & 0.9481 & 0.9978 \\
Adsorption constant, $\mathrm{k}_{1}$ & 0.0367 & - \\
Adsorption constant, $\mathrm{k}_{2}$ & - & 4.9839 \\
\hline
\end{tabular}

\subsection{Isotherm analysis}

Among some of the important isotherm models, the Langmuir and Freundlich models were used to study about the adsorption of ammonium by sewage sludge biochar. Table 2 illustrates the isotherm parameters of $\mathrm{NH}_{4}{ }^{+}$adsorption by sewage sludge biochar (SSB700) using the isotherm models. The values of the regression correlation coefficients $\left(R_{2}\right)$ for the Langmuir and Freundlich models were 0.9717 and 0.847 respectively. By contrast, the experiment data fit well with the Langmuir model. Therefore, the adsorption of ammonium ions by SSB700 was a monolayer adsorption process.

Table 2 The isotherm parameters of $\mathrm{NH}_{4}{ }^{+}$adsorption by sewage sludge biochar (SSB700) for Langmuir and Freundlich

\begin{tabular}{ccc}
\hline Isotherm model & Langmuir & Freundlich \\
\hline $\mathrm{R}^{2}$ & 0.9717 & 0.847 \\
\hline
\end{tabular}

\section{Conclusion}

Based on the characterization tests carried out on the biochar, SSB700 was the most suitable to be used for ammonium adsorption process. In this study, $0.1 \mathrm{~g}$ of SSB700 was proven the most optimum dosage for the adsorption of ammonium. As for contact time analysis, 150 minutes was the most optimum contact time for adsorption of ammonium. $1.2 \mathrm{ppm}$ of ammonium solution was the most efficient initial concentration for adsorption. Finally, through kinetic and isotherm analysis, the adsorption of ammonium by SSB700 was proved to be a monolayer chemisorption process.

\section{Author Contributions:}

Sohaimi KSA: Conceptualization, investigation and writing - original draft preparation

Mohamed AR: Review, editing and formatting

\section{Funding:}

Acknowledgments: The authors would like to express their gratitude to the Department of Chemical Engineering Technology, Faculty of Engineering Technology (FETech) and Institute of Sustainable Agrotechnology (INSAT) of Universiti Malaysia Perlis.

Conflicts of Interest: The authors declare no conflict of interest.

\section{References}

1. Wang YF, Lin F and Pang WQ 2007 J. Hazard. Material. 142 160-164

2. Huang J, Kankanamge NR, Chow C, Welsh DT, Li T and Teasdale PR 2018 J. Environmental Sciences (China), 63 174-197 
3. Chen H, Zhai Y, Xu B, Xiang B, Zhu L, Qiu L and Zeng G 2015 Environmental Technology (United Kingdom), 36(4) 470-478

4. Amonette 2013 Letter Report for Characterization of Biochar, (April).

5. Smith KM, Fowler GD, Pullket S and Graham NJD 2009 Water Research 43 2569-2594

6. Zhang W, Wang S, Zhuang L, Yang Y and Qiu, R 2013 Journal of Analytical and Applied Pyrolysis 102 137-14

7. Hossain MK, Strezov V, Chan KY, Ziolkowski A and Nelson PF 2011 Journal of Environmental Management 92 (1) 223-228

8. Wang X, Lü S, Gao C, Xu X, Zhang X, Bai X, Liu M and Wu L 2014 Chemical Engineering Journal 252 404-414

9. Li Y, Du Q, Wang, X, Zhang P, Wang D, Wang Z and Xia Y 2010 Journal Hazard Mater 183 583-589 